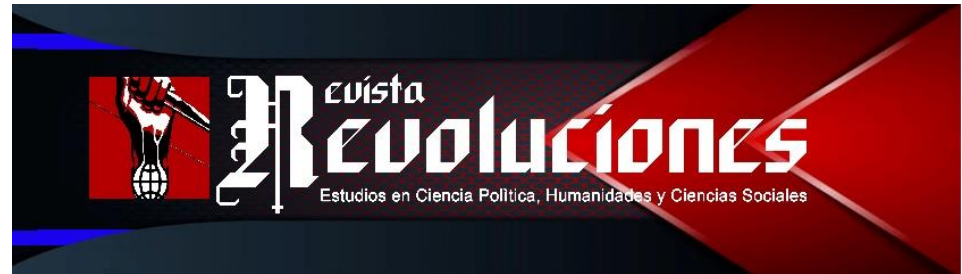

\title{
DE INDEPENDENCIAS A BICENTENARIOS: BALANCES Y PERSPECTIVAS EN TIEMPOS TURBULENTOS
}

\section{From independences to bicentennials: balances and prospects in turbulent times}

\author{
Jesús Wiliam Huanca-Arohuanca ${ }^{1}$ \\ UNIVERSIDAD NACIONAL DE SAN AGUSTÍN \\ DE AREQUIPA \\ PERÚ \\ jhuancaar@unsa.edu.pe \\ https://orcid.org/oooo-0002-7353-1166
}

\author{
Luis Daniel Morán Ramos² \\ UNIVERSIDAD NACIONAL MAYOR DE SAN \\ MARCOS \\ PERÚ \\ lmoranr@unmsm.edu.pe \\ https://orcid.org/oooo-0002-8244-5390
}

DOI: https://doi.org/10.35622/j.rr.2021.05.001

Recibido: 06-VI-2021 / Aceptado: 20-VII-2021 / Actualizado: 28-VII-2021

\section{Resumen}

En tiempos de bicentenarios y crónicas nacionales, el análisis de las guerras de independencia, resulta clave para una mejor comprensión de sus diversas dimensiones y la participación de sus protagonistas. Por ello, este dossier que presenta la Revista Revoluciones, pone al filo de la comunidad académica, ocho investigaciones inéditas que deliberan sobre la coyuntura de guerra y revolución que hace más de 200 años había sido

\footnotetext{
${ }^{1}$ Docente-Investigador del Consejo Nacional de Ciencia, Tecnología e Innovación y el Departamento de Filosofía con mención en Ética y Filosofía Política por la Universidad Nacional de San Agustín de Arequipa [UNSA]. Maestrante en la facultad de Ciencias Jurídicas en Derecho Procesal y Administración de Justicia por la Universidad Católica de Santa María [UCSM]. Docente de Ciencias Sociales, Sociólogo y maestrante en Investigación y Docencia Universitaria por la Universidad Nacional del Altiplano [UNA-P], Perú. En la actualidad dirige la Revista Revoluciones: Estudios en Ciencia Política, Humanidades y Sociales. Así mismo, es revisor de la Revista Educación y Sociedad de la Universidad Ciego de Ávila Máximo Gómez Báez, Cuba. Sus principales líneas de investigación se desprenden en el marco de la teoría del poder, la epistemología, la filosofía decolonial, las políticas neoliberales, dinámicas educativas, las macroestructuras sociológicas y el planteamiento de un nuevo amuyawi para América Latina frente a los núcleos de poder colonial. Su impacto académico obedece a publicaciones de nivel internacional en las bases de datos Scopus, Web of Science y Scielo.

2 Docente Investigador de la Facultad de Educación en la Universidad San Ignacio de Loyola y Docente de Historia en la Facultad de Ciencias Sociales en la Universidad Nacional Mayor de San Marcos (Perú). Actualmente Investigador Renacyt (Carlos Monge, Nivel III) en CONCYTEC-Perú. Además, coordinador del Grupo de investigación Educación y Sociedad en el Perú y América Latina en la Facultad de Educación de USIL. Ha sido becario Roberto Carri (2009-2010) y becario doctoral del Instituto Ravignani de la UBA por el CONICET-Argentina (2011-2016). Doctor en Historia en la Universidad de Buenos Aires (Argentina), Magister en Historia en el Instituto de Altos Estudios Sociales de la Universidad Nacional de San Martín (Argentina) y Licenciado en Historia en la Universidad Nacional Mayor de San Marcos (Perú).
} 
arrojado solo a los indígenas, así mismo, entendiendo que el proceso del estudio de la independencia hasta el bicentenario es una problemática recurrente para los estudiosos del tema, surge la posibilidad de ampliar y conectar los sucesos del pasado con el presente en la búsqueda de la libertad.

Palabras Clave: Independencia, bicentenario, Perú, Historiografía, dossier.

\begin{abstract}
In times of bicentennials and national chronicles, the analysis of the wars of independence is key to a better understanding of their various dimensions and the participation of their protagonists. Therefore, this dossier presented by the Journal Revolutions, puts at the edge of the academic community, eight unpublished investigations that deliberate on the conjuncture of war and revolution that more than 200 years ago had been thrown only to the indigenous, likewise, understanding that the process of the study of independence until the bicentennial is a recurring problem for scholars of the subject, the possibility arises of expanding and connecting the events of the past with the present in the search for freedom.
\end{abstract}

Keyword: Independence, bicentenary, Peru, historiography, dossier.

Los momentos de crisis y tiempos turbulentos, sirven para poder captar la fotografía de una sociedad y las mismas vicisitudes de su itinerario político. En esa perspectiva, así como la pandemia ha evidenciado los grandes problemas de la sociedad peruana y de las naciones a nivel global, en la independencia del Perú la problemática de los hombres y su tiempo, representan un espacio clave para repensar el proceso y su propia historia: porque son aquellas crisis las que muestran los verdaderos intereses de los actores sociales y políticos, las relaciones que todos estos establecen y los juegos políticos en los que se encuentran inmersos la sociedad civil.

Sumado a ello, existe la imposibilidad de cerrar problemas recurrentes que se arrastra desde la intromisión del occidente a las tierras sagradas del incario con la sangre derramada por la ambición y el poder. Cabe mencionar que esa inserción, no solo ha desfigurado por completo la idea de una nación pluricultural, sino también a la moralidad que hasta ahí se había alcanzado, ya que, fueron subsumidos sistemáticamente por la antítesis como idea básica que hoy persiste como: racismo, demagogia, saqueo, corrupción y una serie de mentiras que después de muchas repeticiones se han vuelto verdades absolutas con dominio hacia los desfigurados.

En ese sentido, este dossier sobre la independencia y el bicentenario que se presenta en la Revista Revoluciones: estudios en Ciencia Política, Humanidades y Sociales de 2021, nos permite plantear problemas de forma transversal y entendiendo a los protagonistas desde diversos ángulos y tendencias historiográficas. Sin embargo, el dossier maneja como argumento central, la idea de que solamente se puede comprender la independencia estandarizada cuando hablemos de las independencias y por lo tanto la palabra bicentenario 
también debe dejarse de lado para dar apertura a la denominación de lo que en plural se llamará: bicentenarios.

Además, es fundamental entender que las independencias se configuran mejor si lo analizamos desde una perspectiva más amplia, comparada y conectada. En palabras menos complejas, no podemos estudiar la independencia peruana de forma aislada, sino desde una visión que permita mirarnos en el espejo del otro y más aún, conectando las realidades locales, regionales y continentales, por no decir incluso hasta atlánticas. De modo que, las independencias entonces deben ser reflexionadas desde una amplitud temática y una diversidad de perspectivas historiográficas que permitan comprender mejor el fenómeno y aterrizar los intereses y motivaciones de todos los protagonistas.

Cabe agregar que, la independencia está en deuda con los verdaderos actores negados por la historiografía oficial y a consecuencia muy pocos han manifestado el interés de darles el reconocimiento histórico, situación que ha motivado a esta revista para exponer lo que no se ha expuesto y paralelamente develar que en el Perú existen hombres y mujeres con el compromiso profundo de hacer historia desde la marginalidad, tal como más abajo se presentan.

En ese criterio, con el dossier se busca plantear una tendencia a contracorriente del bicentenario y desde una visión pluralista de las independencias. En un primer momento, Luis Miguel Glave nos ofrece nuevas imágenes de la rebelión andina de 1780 a partir de una serie de documentos de Mariano Isidro de la Barrera, escribiente y compañero de Tupac Amaru, en el mismo tenor, Amparo Kanashiro busca contextualizar los roles que desempeñó Micaela Bastidas, a través de una recopilación de cartas escritas por los escribanos de Micaela, quienes plasmaban sus ideas y solicitudes de manera escrita, en medio de la rebelión entre 1780 a 1781 . Estas fuentes nos permiten advertir nuevas formas de comprender esta etapa de la revolución en los andes y a través de sus líderes y lideresas. Siendo esta última idea pertinente para una nueva historia de los antes excluidos y marginados como fueron las mujeres y los indígenas: por un lado, Monserratt Rivera y Daniel Morán analizan las imágenes sobre el papel de las mujeres en la prensa de Lima, Caracas, Buenos Aires y Santiago de Chile en momentos de cambios y los azarosos eventos de la guerra de independencia, mostrando a las mujeres como sujetos importantes en los sucesos de la revolución y la guerra.

Por otro lado, David Quichua reflexiona sobre "la gente bruta y los pobres miserables" que también lucharon bajo móviles diversos en la independencia en Huamanga. Y como toda guerra necesita de sustento económico, Jesús Yarango, Daniel Morán y Carlos Carcelén hacen un balance del costo de la contrarrevolución a partir del análisis de la Caja Matriz de Lima y los gastos de la guerra en tiempos del Virrey Abascal (1806-1816). Así como la guerra causó estragos en la población, las epidemias y las enfermedades como la viruela afectó también los acontecimientos del momento, por ello Arnaldo Mera estudia la continuidad de la prevención de dicha enfermedad en el Perú entre el régimen de Abascal, Pezuela, La Serna y el Protectorado de San Martín. 
ISSN: 2710-0499 ISSN-L: 2710-0480

Por tanto, se presentan dos textos de reflexión que cierran este dossier: por un lado, Raúl Chanamé-Orbe analiza a la República como problema histórico, tema de por sí importante si entendemos que su estudio evidencia la necesidad de repensar la instalación de la república y el surgimiento de los estados nación, donde el Perú juega un papel esencial; finalmente, Héctor Palza Becerra nos muestra lo complejo y arduo que significó el duro aprendizaje del camino a la libertad y el republicanismo en el país.

Evidentemente, este dossier no es un conjunto de trabajos que cierran una historia muy problemática como fue el de la independencia o las independencias en un contexto de los bicentenarios, sino más bien representan primeras aproximaciones diversas por comprender de una forma diferente aquel complejo proceso de la guerra y la revolución. De manera que, en pleno bicentenario de la independencia, consideramos que no tenemos cosa alguna que celebrar, pero si diversos episodios y protagonistas que conmemorar, revalorando su papel histórico y sus aportes en esta turbulenta coyuntura y su largo camino republicano como el de los cambios y las permanencias; o, al estilo de Basadre, de problemas y posibilidades.

Agradecemos enormemente a los autores (as) que presentan su propuesta en este dossier de la Revista Revoluciones y a los editores por confiar en este conjunto de trabajos que abren nuevas perspectivas y problemas para una mejor comprensión de la independencia del Perú. Sin investigación no podemos conmemorar el bicentenario o los bicentenarios, como sin problematización tampoco podemos entender aquel proceso histórico. 